\title{
Nickel Wick by Continuous Freeze-Casting: Influences of the Particle Size on the Capillarity and Mechanical Properties
}

\author{
Pedro Javier Lloreda-Jurado *(D), Laura Chicote, Ernesto Chicardi (D) and Ranier Sepúlveda *(D) \\ Departamento de Ingeniería y Ciencia de los Materiales y del Transporte, E.T.S. de Ingeniería, \\ Universidad de Sevilla, Camino de los Descubrimientos, s/n., 41092 Sevilla, Spain; lauchigar@alum.us.es (L.C.); \\ echicardi@us.es (E.C.) \\ * Correspondence: plloreda@us.es (P.J.L.-J.); rsepulveda@us.es (R.S.)
}

check for updates

Citation: Lloreda-Jurado, P.J.;

Chicote, L.; Chicardi, E.; Sepúlveda, R. Nickel Wick by Continuous FreezeCasting: Influences of the Particle Size on the Capillarity and Mechanical Properties. Materials 2021, 14, 4340. https://doi.org/10.3390/ma14154340

Academic Editor: Jordi Sort

Received: 8 July 2021

Accepted: 1 August 2021

Published: 3 August 2021

Publisher's Note: MDPI stays neutral with regard to jurisdictional claims in published maps and institutional affiliations.

Copyright: (c) 2021 by the authors. Licensee MDPI, Basel, Switzerland. This article is an open access article distributed under the terms and conditions of the Creative Commons Attribution (CC BY) license (https:// creativecommons.org/licenses/by/ $4.0 /)$.

\begin{abstract}
The aim of this work was to study the effect of the particle size range, the freeze casting temperature and sintering temperature on the capillarity performance and mechanical properties of Ni wicks manufactured by freeze-casting. The use of $\mathrm{Ni}$ /camphene-polystyrene suspensions creates wicks with an open porosity above $80 \%$ and average pore sizes of $38 \mu \mathrm{m}$ to $17 \mu \mathrm{m}$ by tailoring the particle size ranges and freezing temperatures employed. The incorporation of PS and the use of a continuous freeze-casting process reduces the particle sedimentation and generates a highly interconnected pore structure with regular pore sizes across the sample. The capillarity performances exhibit a fast and complete water adsorption, especially in $\mathrm{Ni}$ wicks freeze-casted at $10{ }^{\circ} \mathrm{C}$ and sintered at $800^{\circ} \mathrm{C}$, but only when the smaller particle size range is used do $\mathrm{Ni}$ wicks achieve sufficient mechanical strength.
\end{abstract}

Keywords: Ni; wicks; freeze-casting; camphene; polystyrene

\section{Introduction}

The manufacture of porous metal materials has gained significant interest in the scientific community during the last decades due to their low density, good capacity for energy absorption, and high specific surface characteristics. These properties, together with the nature of the material and their pore morphology, give them a great variety of applications, such as battery electrodes [1], sound barriers material [2], filters/catalysts [3,4], biomedical implants [5,6], cushion dampers [7], etc. Furthermore, if the porosity of these materials is interconnected, other attractive characteristics such permeability, infiltration, and heat exchange arise, being the manufacture of wicks one of its most significant applications.

Wicks are the main component of loop heat pipe (LHP) systems, highly efficient heat transfer devices quite appreciated in the aerospace and electronics industries [8-10]. The wicks allow the coolant to flow self-propelled through its porous structure without the need for an external pump. A schema of the operation of a wick is displayed in Figure 1. LHPs are composed of vapor and liquid lines, condenser, evaporator, compensation chamber, and a wick [11]. Thus, the wick is a porous part with a tailored pore structure, high permeability, improved capillary performance, and made of a low thermal conductivity material such as $\mathrm{Ni}$ [12] or stainless steel [13] to reduce the heat transfer. Usually, an open porosity of about 50 to $75 \%$ with pore sizes ranges from 1 to $100 \mu \mathrm{m}$, and sufficient mechanical strength (above $10 \mathrm{MPa}$ ) for dimensional tolerance adjustment is required $[9,11]$.

Traditionally, wicks have been manufactured by cold pressing using space holders [14] or loose sintering technologies $[15,16]$. As an alternative, the freeze-casting technique deserves special mention due to its numerous advantages, including the possibility of acquiring complex geometries, low cost-effectiveness ratio, eco-friendly, and scalability $[8,17]$. This technique is based on the direct solidification of a particle suspension, where the solvent crystals push and compact the dispersed particles towards the free spaces of their 
contour. The resulting porosity of the material is now the space left by the solvent crystals when sublimated. Morphology features and pore size can be altered by: (1) using different solvents—-water for lamellar pores or camphene for dendritic crystallization - and (2) the control of thermo-kinetic parameters, such as the solidification rate or thermal gradient $[18,19]$.

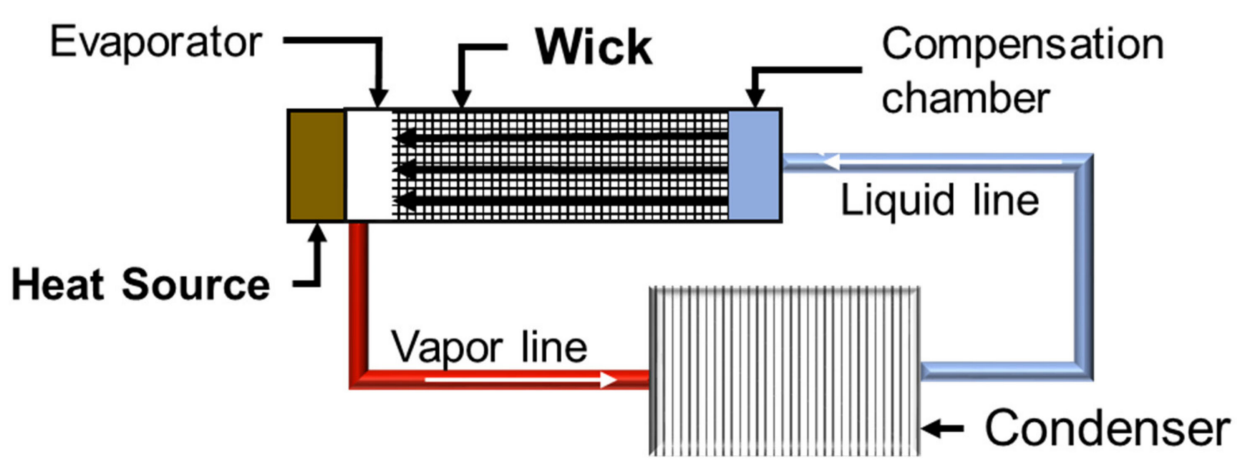

Figure 1. Schema of a loop heat pipe.

In a previous work [17], nickel wicks were manufactured by freeze-casting using $\mathrm{NiO}$ nanoparticles of $40 \mathrm{~nm}$ in diameter. However, the use of the freeze-casting technique to develop porous metal materials (such as the abovementioned wicks) presents some problems. The high density and the large size (above few microns) of the metallic particles increase the undesirable sedimentation phenomena. Therefore, specific technical variations must be implemented to overcome this disadvantage.

According to a modified version of Stokes' law [20], the sedimentation rate of a particle in a solution depends on the densities of the particle and the liquid, the dynamic viscosity of the liquid vehicle, and most importantly the particle size. Therefore, this work is focused on the manufacture and characterization of $\mathrm{Ni}$ wicks using commercial grade Ni particles implementing these experimental variations: (1) reduction of the metallic particle size through sieving; (2) increasing the liquid camphene viscosity by adding polystyrene of a high molecular weight [21] and, (3) the use of a continuous freeze-casting process to inhibit the particle motion across the sample height.

\section{Experiment and Method}

\subsection{Wick Manufacturing}

Ni powder $(<150 \mu \mathrm{m}$ in diameter and $99.99 \%$ of purity, Sigma Aldrich, St. Louis, MO, USA) was firstly sieved to obtain three different particle size ranges: $44-32 \mu \mathrm{m}, 32-25 \mu \mathrm{m}$, and less $25 \mu \mathrm{m}$ denoted as L (large), M (medium), and S (Small) ranges, respectively. High molecular weight polystyrene (PS, Mw $=350,000 \mathrm{~g} / \mathrm{mol}$, Sigma Aldrich, St. Louis, MO, USA) was incorporated into camphene (95\% purity, Sigma Aldrich, St. Louis, MO, USA) in a $60 \mathrm{~mL}$ seal glass vessel rotating at $100 \mathrm{rpm}$ using a ball milling (lab-made) equipment inside an incubator (INCU-Line IL 23, VWR, Llinars del Vallès, Spain) at $60^{\circ} \mathrm{C}$ for approximately $2 \mathrm{~h}$ to obtain a camphene- 10 vol.\% PS solution. Once the PS was completely dissolved, a 10 vol. $\%$ of Ni powder with an L, M, or S particle size range was incorporated into the glass vessel and dispersed under the same conditions for 24 $\mathrm{h}$, to achieve $\mathrm{Ni} /$ camphene-PS suspensions with those different particle size ranges. A ball-to-powder ratio (BPR) of 1:9 with stainless steel balls of $3 \mathrm{~mm}$ in diameter was used during the ball milling process. After dispersion, the suspension was immediately poured into a cylindrical mould made of silicone tube with a copper base precooled inside an incubator (INCU-Line IL 68R, VWR, Llinars del Vallès, Spain) at $10^{\circ} \mathrm{C}, 25^{\circ} \mathrm{C}$, or $40^{\circ} \mathrm{C}$ of 
freezing temperature $\left(T_{c}\right)$. The resulting green samples exhibit dimensions of $10 \mathrm{~mm}$ in diameter by $26 \mathrm{~mm}$ in height, approximately.

Sublimation of solid camphene within the green samples was completed employing a freeze-dryer (LyoQuest, Telstar, Madrid, Spain) after $24 \mathrm{~h}$ at $30{ }^{\circ} \mathrm{C}$ under vacuum. Green samples underwent heat treatment at $400{ }^{\circ} \mathrm{C}$ for $2 \mathrm{~h}$ for organic burn-out followed by a sintering process at $800{ }^{\circ} \mathrm{C}$ for $1.5 \mathrm{~h}$ in a tubular furnace (Thermolyne 21100 , Sigma Aldrich, St. Louis, MO, USA) under reducing conditions with $\mathrm{Ar}-20 \mathrm{H}_{2}$ reducer gas flow (Air Liquide, Seville, Spain) of $0.5 \mathrm{NL} \cdot \mathrm{min}^{-1}$ to prevent Ni oxidation and enhance the sintering process. An extra batch of samples was also sintered at $600{ }^{\circ} \mathrm{C}$ to study the influence of sintering temperature in the porous structure. Heating and cooling rates were set at $1^{\circ} \mathrm{C} \cdot \mathrm{min}^{-1}$ and $5^{\circ} \mathrm{C} \cdot \mathrm{min}^{-1}$, respectively, to prevent cracks or sample distortions. Final sintered samples measured approximately $8.5 \mathrm{~mm}$ in diameter and $22 \mathrm{~mm}$ in height.

Sintered samples were denoted as $\mathrm{X} / \mathrm{YY} / \mathrm{ZZZ}$ according to the particle size range (X: $\mathrm{L}, \mathrm{M}$, or $\mathrm{S}$ ), the freezing temperature (YY: 10,25 , or $40^{\circ} \mathrm{C}$ ), and the sintering temperature (ZZZ: 600 or $800^{\circ} \mathrm{C}$ ). For example, the $\mathrm{L} / 25 / 600$ sample was fabricated with the L (large particle size range), cooled at $25^{\circ} \mathrm{C}$, and sintered at $600{ }^{\circ} \mathrm{C}$.

\subsection{Wick Characterization}

During freezing, the temperature profile across sample height $(h)$ was recorded using four thermocouples (type T) inserted in the silicone tube at $0,8,16$, and $24 \mathrm{~mm}$ from the mold base. The freezing rate $\left(F R^{h}\right)$ was obtained as the time to reach freezing temperature $T_{\mathcal{C}}\left(40,25\right.$, and $\left.10{ }^{\circ} \mathrm{C}\right)$ at the different $h$ after pouring. Equation (1) shows the calculation procedure:

$$
F R^{h}=\frac{60-T_{c}}{t_{h}}\left[\frac{{ }^{\circ} \mathrm{C}}{\min }\right],(h=0,8,16,24 \mathrm{~mm})
$$

where $t_{h}$ is the time to reach $T_{c}$ at $h$ when the pouring ends.

The bulk density $(\rho)$, open porosity $\left(P_{O}\right)$, and close porosity $\left(P_{C}\right)$ of each sample were determined through Archimedes' method, which involved soaking the wick samples in hot water for $24 \mathrm{~h}$ (tests were repeated 3 times). Several optical microscopy (OM) images were taken using an Eclipse MA100N optical microscope (Nikon, Leuven, Belgium) on the central axial plane at different heights to estimate the average pore size $(\varnothing)$ and wall thickness $(\tau)$, and total porosity $\left(P_{T}\right)$ across the sample height. An area of approximately $5 \mathrm{~mm}^{2}$ (with at least 5 OM images) was analyzed at each $h$ to ensure statistical accuracy. OM images were processed using the Image ${ }^{\circledR}$ software $(1.53 \mathrm{v}$, U. S. National Institutes of Health, Bethesda, MD, USA) by the non-redundant maximum-sphere-fitted image analysis technique [22].

The capillary performance $(C P)$, i.e., the amount of liquid absorbed over time, was determined for Ni wicks sintered at $800{ }^{\circ} \mathrm{C}$ using similar setups reported elsewhere [23-25]. The top sample surface was carefully placed in contact with a water reservoir using a micrometric screw. The weight of water adsorbed overtime was ascertained using an electronic analytical balance (Explorer Pro EP114C, OHAUS, Nänikon, Switzerland). Tests were repeated 3 times after drying the samples at $110^{\circ} \mathrm{C}$ overnight. The top sample surface was placed in direct contact to simulate the effect of impregnation at the secondary wick and the capillarity suction towards the primary wick. The water mass absorbed fraction was calculated as the mass of water absorbed by the maximum capacity given for the interconnected porosity $\left(P_{O}\right)$ of the Ni wick.

Uniaxial compression strength tests of the $\mathrm{L} / 25 / 800, \mathrm{M} / 25 / 800$, and $\mathrm{S} / 25 / 800$ samples were carried out at room temperature using a universal mechanical testing machine (AG-IS, Shimadzu, Grossenbaum, Germany) with a $10 \mathrm{KN}$ load cell and a crosshead speed of $2 \mathrm{~mm} \cdot \mathrm{min}^{-1}$. Tests were performed on three cylindrical samples of $8 \mathrm{~mm}$ in diameter and $4 \mathrm{~mm}$ in height which were cut from the sintered samples at the bottom $(h=5.5 \mathrm{~mm})$ and top $(h=16.5 \mathrm{~mm})$ sections. All tests were stopped when a constant plateau on the applied stress is achieved. 


\section{Results and Discussion}

\subsection{Ni Wick Microstructure}

According to the temperature profile recorded during continuous freeze-casting, no significant variation of the freezing behavior was observed across the sample height or with the particle size range employed. However, the Ni/camphene-PS suspensions poured at $60^{\circ} \mathrm{C}$ did not reach the melting point of camphene at any moment, the suspensions were instantly solidified and the $F R^{h}$ remains constant throughout $h . F R^{h}$ and $t_{h}$ were estimated in 2,3 , and $5{ }^{\circ} \mathrm{C} \cdot \mathrm{min}^{-1}$, and 10,12 , and $10 \mathrm{~min}$ for the freezing temperature of 40,25 , and $10{ }^{\circ} \mathrm{C}$, respectively. Table 1 shows the bulk density $(\rho)$, open porosity $\left(P_{O}\right)$, and close porosity $\left(P_{C}\right)$ of the sintered Ni wicks. Clearly, the $\rho$ was increased with the use of smaller particles and the reduction of $T_{\mathcal{C}}$ for samples freeze-casted at 40,25 and $10{ }^{\circ} \mathrm{C}$. This effect is attributed to the improvement in the particle stacking during freezing with the reduction of the particle size range and the higher thermal gradient applied. The $P_{O}$ was diminished with the reduction of the particle size range, where final $P_{O}(72-83 \%)$ showed values close to the theoretical maximum of $85 \%$, which correspond to the volume of the fugitive phases (camphene and PS). Therefore, the use of a continuous freeze-casting process prevents most camphene losses. Finally, the $P_{C}$ calculated shows higher values in the samples fabricated with the higher particle size range L. A significant aspect was detailed on sample $S / 40 / 800$, where the $P_{C}$ was the highest of all sintered samples. This behavior could be attributed to the formation of close pores due to particle coalescence during sintering. The reduction of the sintering temperature to $600{ }^{\circ} \mathrm{C}$ produced an overall reduction of the sample $\rho$ and $P_{C}$, with a respective increment in the $P_{O}$.

Table 1. Bulk density $(\rho)$, open $\left(P_{O}\right)$, and close $\left(P_{C}\right)$ porosity of the sintered Ni wicks.

\begin{tabular}{cccc}
\hline Sample & $\boldsymbol{\rho} \mathbf{( \mathbf { g } \cdot \mathbf { c m } ^ { - 3 } )}$ & $\boldsymbol{P}_{\boldsymbol{O}} \mathbf{( \% )}$ & $\boldsymbol{P}_{\boldsymbol{C}} \mathbf{( \% )}$ \\
\hline $\mathrm{L} / 40 / 800$ & 1.09 & 81 & 7 \\
$\mathrm{~L} / 25 / 800$ & 1.22 & 81 & 5 \\
$\mathrm{~L} / 10 / 800$ & 1.48 & 78 & 5 \\
\hline $\mathrm{M} / 40 / 800$ & 1.24 & 83 & 3 \\
$\mathrm{M} / 25 / 800$ & 1.29 & 81 & 4 \\
$\mathrm{M} / 10 / 800$ & 1.51 & 79 & 9 \\
$\mathrm{~S} / 40 / 800$ & 1.65 & 72 & 2 \\
$\mathrm{~S} / 25 / 800$ & 2.01 & 75 & 1 \\
$\mathrm{~S} / 10 / 800$ & 2.09 & 75 & 4 \\
$\mathrm{~L} / 25 / 600$ & 1.11 & 83 & 1 \\
$\mathrm{M} / 25 / 600$ & 1.16 & 84 & \\
$\mathrm{~S} / 25 / 600$ & 1.38 & 83 & \\
\hline
\end{tabular}

Figure 2 shows the pore structure evolution in the Ni wicks sintered at $800{ }^{\circ} \mathrm{C}$ across the sample height when different particle size ranges and freezing temperatures were employed. According to the OM micrographs (black contrast), the pore distribution was highly interconnected, with no significant differences across the sample height regardless of the particle size range or freezing profile employed. The pore size was reduced with the use of the smaller particle size range and especially with the decrease of the freezing temperature. As the particle size diminishes, the critical velocity for particle engulfment increased and the solidification front is enabled to push the particle within the interdendritic spaces $[19,26]$. Thus, the particles get surrounded by the solid front creating a more continuous pore network with smaller pore sizes. Also, as the number of particles per volume increased due to the particle size reduction and the $T_{c}$ decreased, the branching of the growing solid front is enhanced resulting in much higher interconnectivity of the pores [27]. 


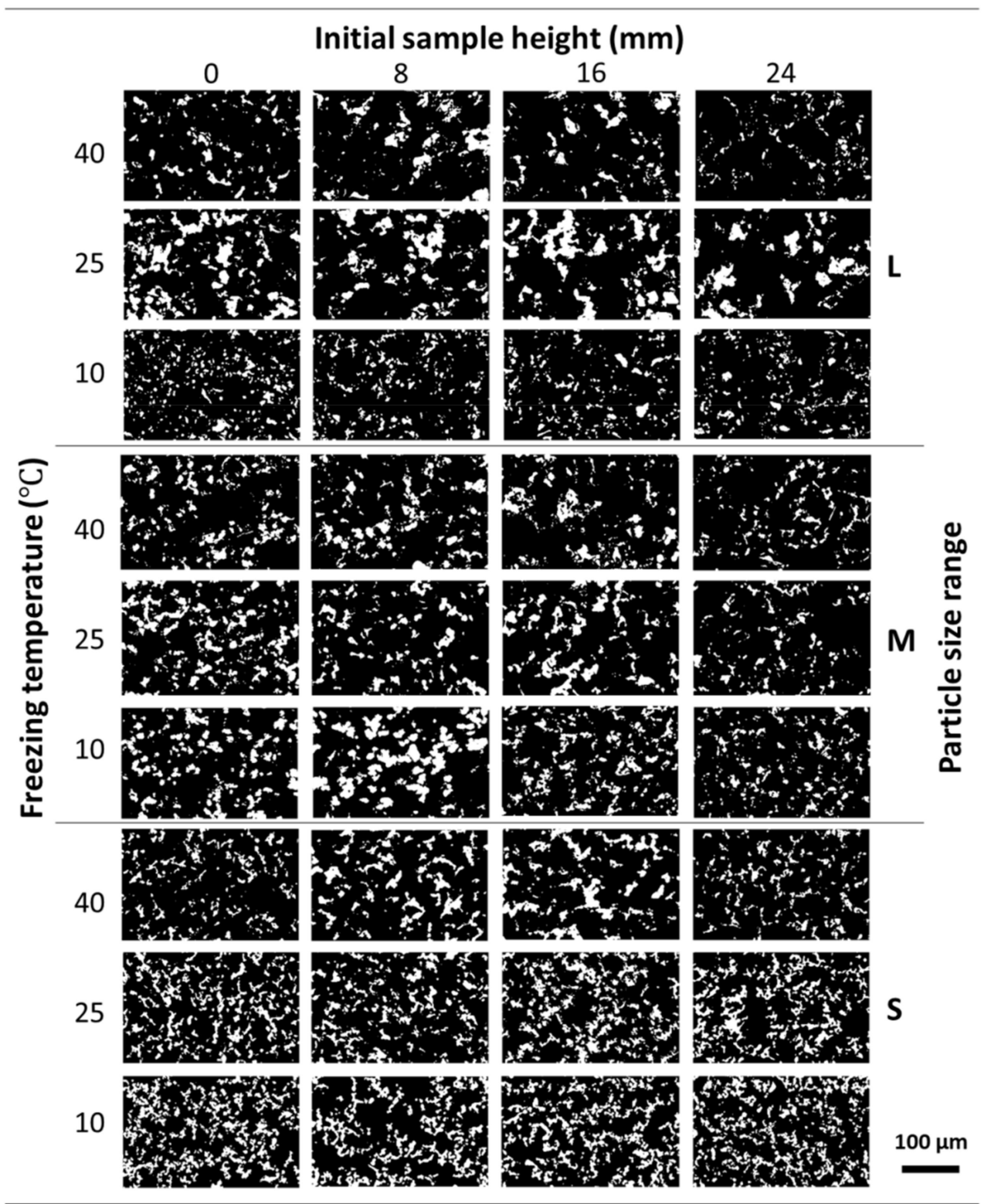

Figure 2. Evolution of the pore structure of the Ni wicks sintered at $800{ }^{\circ} \mathrm{C}$ across the sample height. OM micrographs show the effect of the different particle size range ( $\mathrm{L}, \mathrm{M}$, and $\mathrm{S}$ ) and freezing temperature $\left(40,25\right.$, and $\left.10^{\circ} \mathrm{C}\right)$ employed. Pores are shown in black and Ni walls were showed in white contrast.

The $P_{T}$ of the Ni Wicks fabricated did not vary significantly across the sample height (Table 2). This behavior could be attributed to the following causes: (1) the lower tendency to sedimentation of the Ni particles due to the increment on the camphene viscosity by the addition of PS [21], which allows the optimal dispersion of Ni particles and, (2) the freezing procedure employed acts as a continuous freeze-casting method, as the maximum temperature recorded by the thermocouple during casting did not go over the camphene melting point, i.e., the $\mathrm{Ni}$ /camphene-PS suspensions were solidifying as poured. The samples L, M, S/25/600 show a higher $P_{T}$ as compared with corresponding Ni wick samples sintered at $800{ }^{\circ} \mathrm{C}$ due to the inherent lower densification. As $P_{T}$ was calculated using image analysis, no direct correlation could be made with the porosity obtained by Archimedes' method but can be used to compare the porosity across the sample height. Moreover, the lower sintering temperature diminished the densification process of the $\mathrm{Ni}$ particles, as showed Tables 1 and 2. Figure 3 shows the pore structure evolution of the Ni 
wick sintered at 600 and $800{ }^{\circ} \mathrm{C}$ across the sample height for the different particle sizes range employed. The lower sintering temperature promoted less densification, as the $\mathrm{Ni}$ wall (white contrast) looks thinner and scattered.

Table 2. Total porosity $\left(P_{T}\right)$ of the sintered Ni wicks across the initial sample height.

\begin{tabular}{ccccc}
\hline \multirow{2}{*}{ Sample } & \multicolumn{4}{c}{$\boldsymbol{P}_{\boldsymbol{T}} \mathbf{( \% )}$ According to the Initial Sample Height $(\mathbf{m m})$} \\
\cline { 2 - 5 } & $\mathbf{0}$ & $\mathbf{8}$ & $\mathbf{1 6}$ & $\mathbf{2 4}$ \\
\hline $\mathrm{L} / 40 / 800$ & 86 & 85 & 85 & 86 \\
$\mathrm{~L} / 25 / 800$ & 83 & 84 & 84 & 85 \\
$\mathrm{~L} / 10 / 800$ & 87 & 89 & 89 & 88 \\
\hline $\mathrm{M} / 40 / 800$ & 89 & 89 & 89 & 93 \\
$\mathrm{M} / 25 / 800$ & 85 & 86 & 87 & 89 \\
$\mathrm{M} / 10 / 800$ & 83 & 85 & 86 & 88 \\
\hline $\mathrm{S} / 40 / 800$ & 86 & 84 & 82 & 86 \\
$\mathrm{~S} / 25 / 800$ & 79 & 80 & 80 & 81 \\
$\mathrm{~S} / 10 / 800$ & 77 & 77 & 77 & 76 \\
\hline $\mathrm{L} / 25 / 600$ & 90 & 94 & 93 & 93 \\
$\mathrm{M} / 25 / 600$ & 92 & 92 & 93 & 93 \\
$\mathrm{~S} / 25 / 600$ & 87 & 91 & 93 & 92 \\
\hline
\end{tabular}

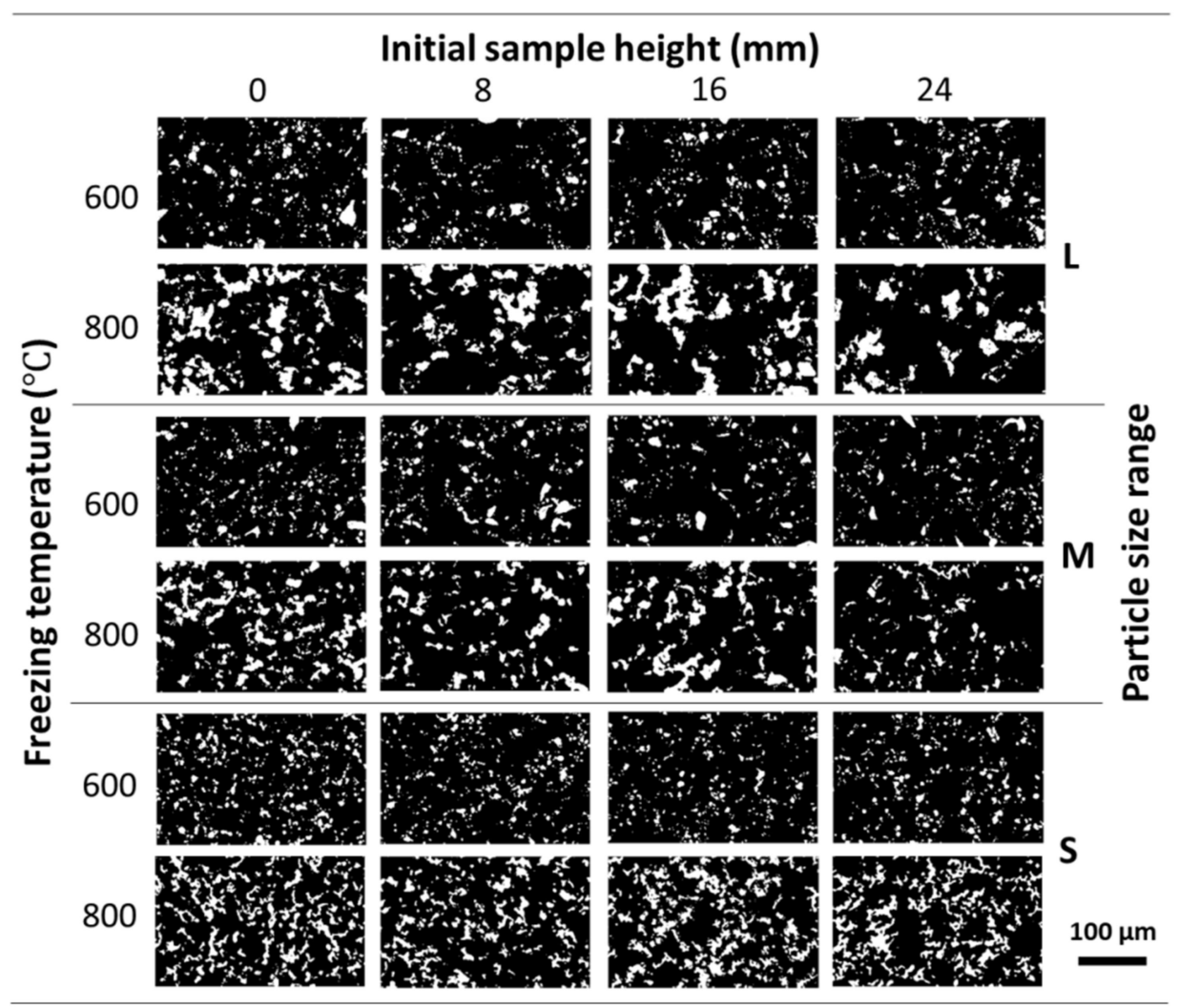

Figure 3. Evolution of the pore structure of the Ni wicks freeze-casted at $25{ }^{\circ} \mathrm{C}$ across the initial sample height. OM micrographs show the effect of the different particle size ranges (L, M, and $\mathrm{S})$ and sintering temperatures $\left(600\right.$, and $\left.800^{\circ} \mathrm{C}\right)$ employed. Pores are shown in black and Ni walls were in white contrast.

The Ni wicks showed a wide pore size distribution (Figure 4) regardless of the processing parameter. Bottom-parts of Ni wicks L/40-10/800, M/40/800, and M/25/800 presented smaller average pore sizes $(\varnothing)$, and the cumulative distribution moves to lower 
pore sizes. This behavior corresponds to the zones subjected to a more intense FR where larger particle size ranges promoted the particle engulfment rather than the particle pushing. Overall, as the $T_{c}$ reduces, the cumulative pore size distribution becomes narrow and the average pore size $(\varnothing)$ moves to lower values with the lower particle size range. Samples L/40/800 and S/10/800 showed a $\varnothing$ of 38 and $17 \mu \mathrm{m}$, respectively and, the $50 \%$ cumulative pore size of the $\mathrm{Ni}$ wicks exhibited a reduction with $\mathrm{T}_{\mathrm{c}}$ and the particle size range used. According to Figure 5, Ni wicks exhibited similar $\varnothing$ for sintering temperatures of $600{ }^{\circ} \mathrm{C}$ (Figure 5a) and $800{ }^{\circ} \mathrm{C}$ (Figure 5b). However, wicks sintered at $600{ }^{\circ} \mathrm{C}$ did not present sufficient mechanical strength due to the poor particle necking formed during sintering (Figure 3).
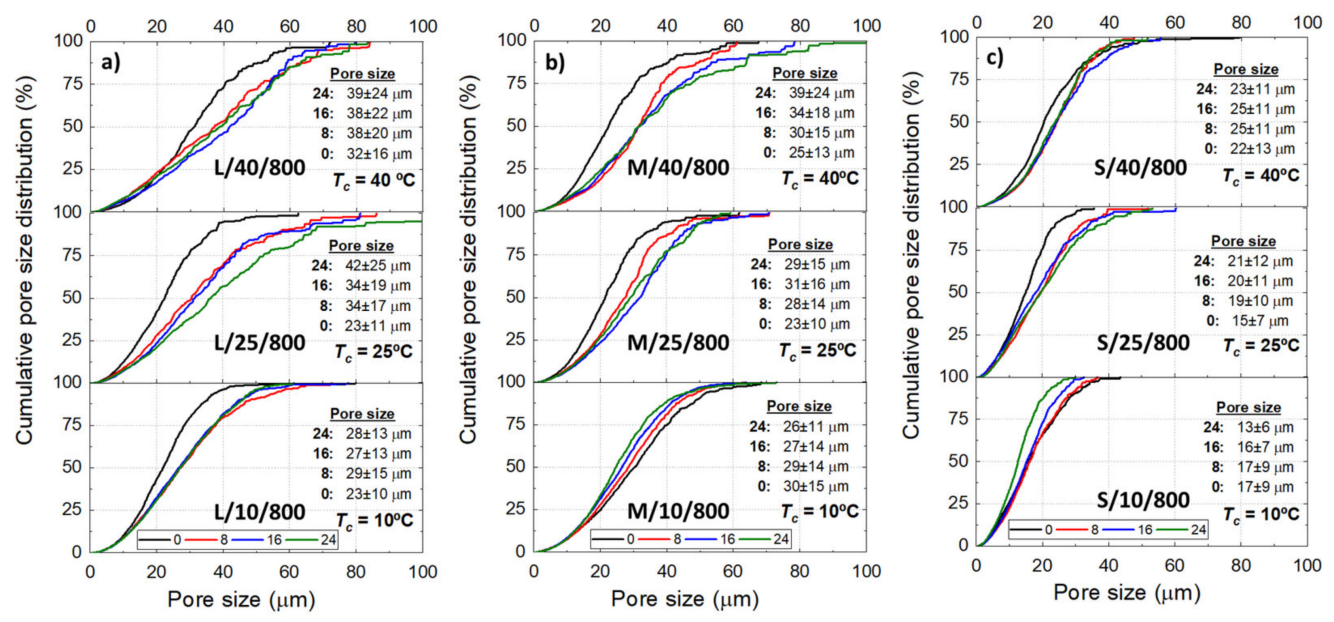

Figure 4. Cumulative pore size distribution of the Ni wick sintered at $800{ }^{\circ} \mathrm{C}$ according to the initial sample height $(h=0,8,16$, and $24 \mathrm{~mm})$, freezing temperature $\left(T_{\mathcal{c}}=40,25\right.$, and $\left.10{ }^{\circ} \mathrm{C}\right)$, and de particle size range L (a), M (b), and S (c). Tables inserted show the average pore size $(\varnothing)$ at the respective $h$.

\subsection{Capillary Performance (CP) of the Ni Wicks}

Figure 6 shows the water mass absorbed fraction of the fabricated Ni wicks. A minimum fraction of 0.85 of the total volume was filled during the test in all samples because of the tortuosity of the interconnected porosity (Figure 2), where pore branching and pore section variations impede the liquid transportation. It should be noticed how samples $\mathrm{L} / 40 / 800, \mathrm{M} / 40 / 800$, and $\mathrm{L} / 25 / 800$ reach a plate value above 1 , which could be attributed to the extra amount of water retained at the wick surfaces, especially those not in contact with the liquid reservoir. This situation was observed in the wicks with bigger pore sizes feeling wet after the capillarity test. Ni wicks freeze-casted at $10^{\circ} \mathrm{C}$ have shown a higher mass absorption rate. The presence of small pore size and high pore interconnectivity promoted by the higher FR applied are responsible for this behavior. Similar results were reported elsewhere [17]. Wicks labeled as S/40/800 and S/10/800 showed the lowest water mass absorbed fraction and rate, attributing to the low $\mathrm{P}_{\mathrm{O}}$ reached leading to minor open porosity since they exhibited similar pore sizes compared with $\mathrm{L} / 10 / 800$ and $\mathrm{M} / 10 / 800 \mathrm{Ni}$ wick. These results indicated the importance of achieving a high tortuosity pore structure with a small pore size during wick manufacturing to promoted high absorption rates. 

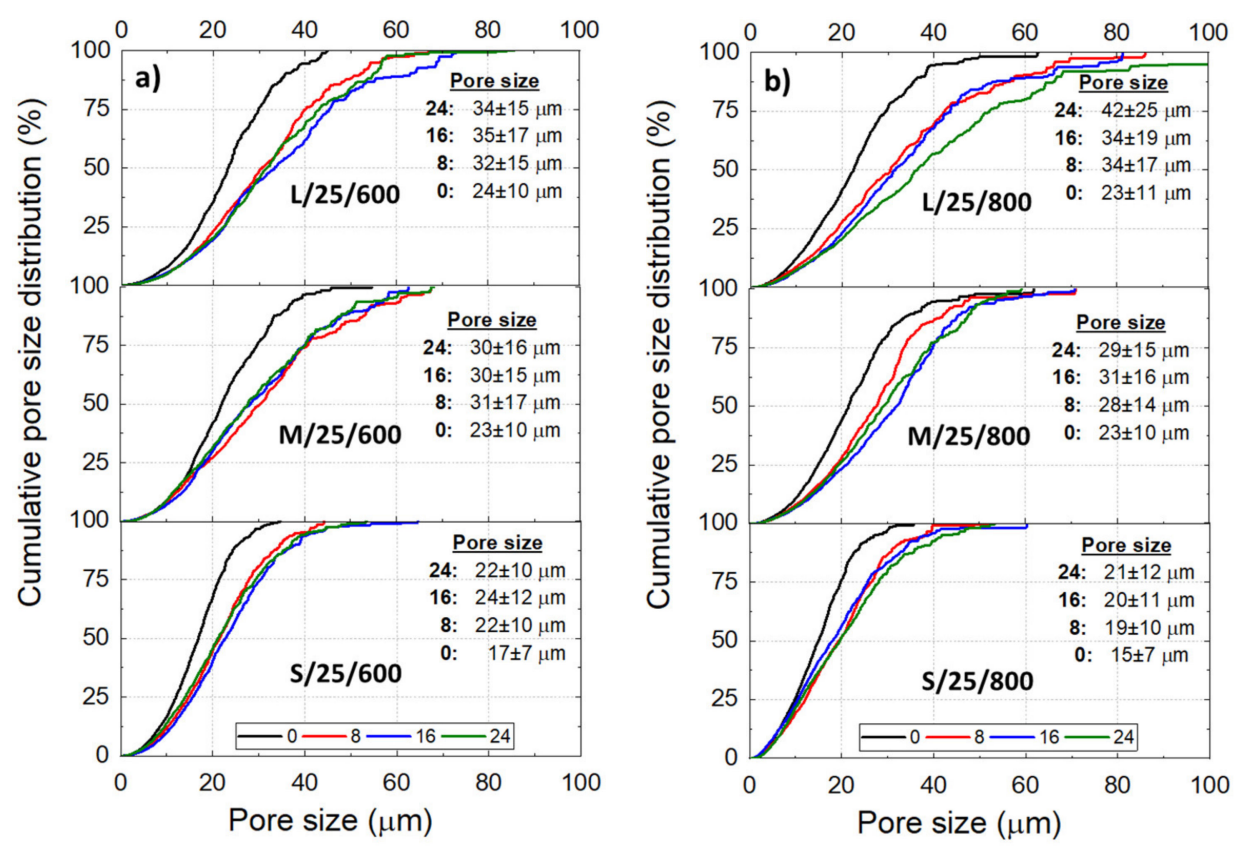

Figure 5. Cumulative pore size distribution of the Ni wicks freeze-casted at $25^{\circ} \mathrm{C}$ according to the initial sample height $(h=0,8,16$, and $24 \mathrm{~mm}$ ), particle size range (L, M, and S), and the sintering $600(\mathbf{a})$ and $800^{\circ} \mathrm{C}(\mathbf{b})$. Tables inserted show the average pore size $(\varnothing)$ at the respective $h$.

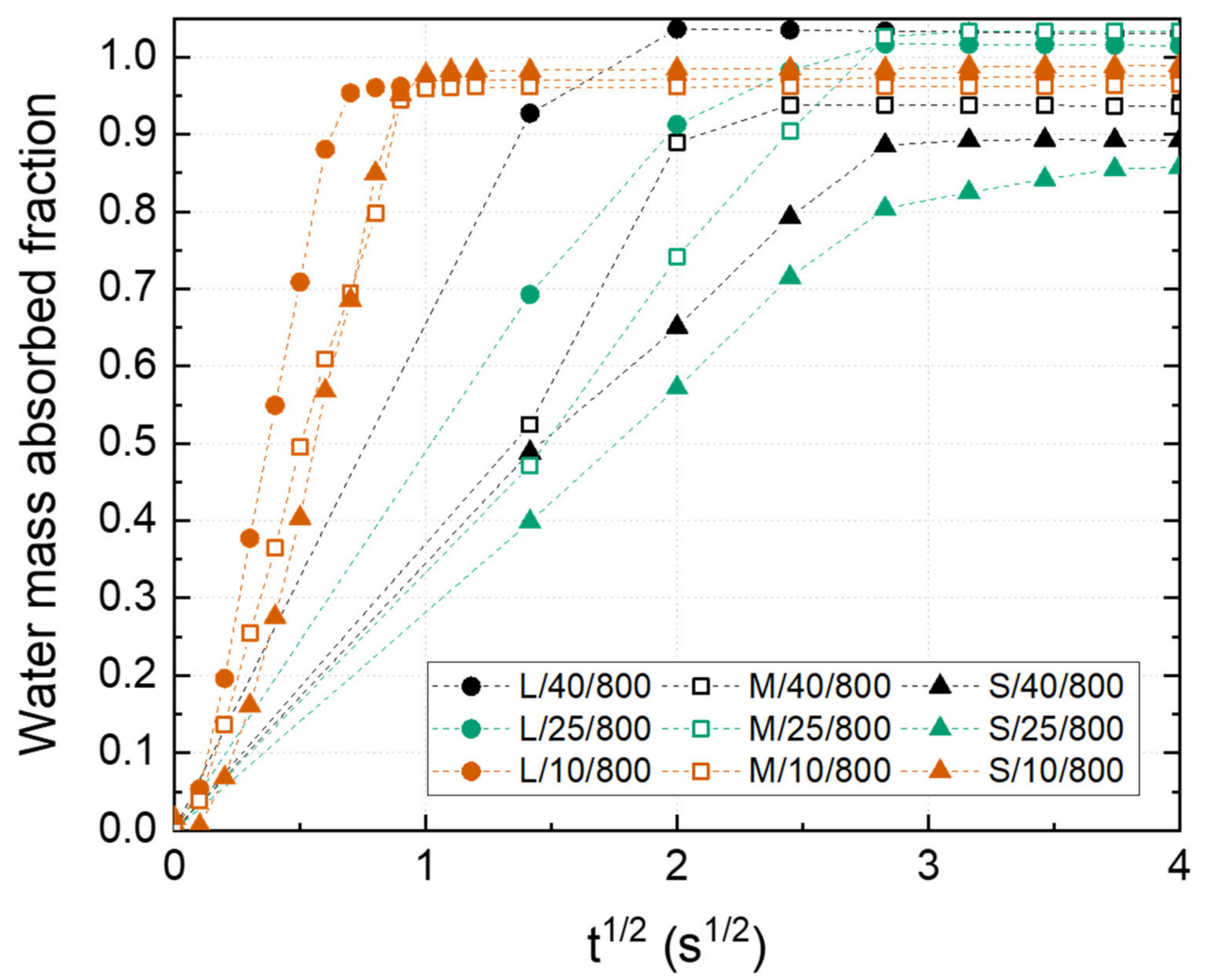

Figure 6. Water mass absorbed fraction of the Ni wicks sintered at $800{ }^{\circ} \mathrm{C}$ as a function of the particle size range $(\mathrm{S}, \mathrm{M}, \mathrm{L})$ and the freezing temperature $\left(10,25\right.$, and $\left.40{ }^{\circ} \mathrm{C}\right)$.

\subsection{Mechanical Properties}

Compression tests were performed in the Ni wicks to evaluate the influence of the $P_{O}, \varnothing$, and the particle size range employed over the mechanical response. Figure 7 shows 
the strain-stress curves obtained for the Ni wicks. In general, the use of a smaller particle size range for manufacturing the $\mathrm{Ni}$ wicks improved the compression strength. The effects could be attributed to the increment in the bulk density achieved since the particle size range is reduced. In addition, a significant influence on the $\varnothing$ can be seen through testing the top and bottom sections of the Ni wicks. All bottom samples have a $\varnothing$ smaller than the top samples; therefore, the influence of this pore size reduction is visible as all bottom samples strain-stress curves were above the top-sample curves. L/25/800 and M/25/800 top curves showed similar mechanical behavior due to comparable $P_{O}$ observed for both $\mathrm{Ni}$ wicks. In the case of bottom curves of $\mathrm{L} / 25 / 800$ and $\mathrm{M} / 25 / 800$, the particle size reduction increased the mechanical strength, but these Ni-wicks samples showed similar $P_{O}$ and $\varnothing$. However, higher densification was obtained in the M/25/800 Ni wick (Table 1), which is responsible for the better mechanical performance. Ni wicks manufactured with the particle size range $\mathrm{S}$ and freeze-casted at $25^{\circ} \mathrm{C}$ showed the highest compression strength, indeed these samples showed the highest density $\left(2.01 \mathrm{~g} \cdot \mathrm{cm}^{3}\right)$, and the $\varnothing$ was $20 \mu \mathrm{m}$ and $15 \mu \mathrm{m}$ at the top and bottom section, respectively. These results indicated that the continuous freezes-casting technique is capable of manufacturing Ni wicks. The ability to use commercial grade Ni particles simplifies the fabrication process of tailored wicks for the electronic industry, where the miniaturization and intricate shapes requirements could be satisfied.

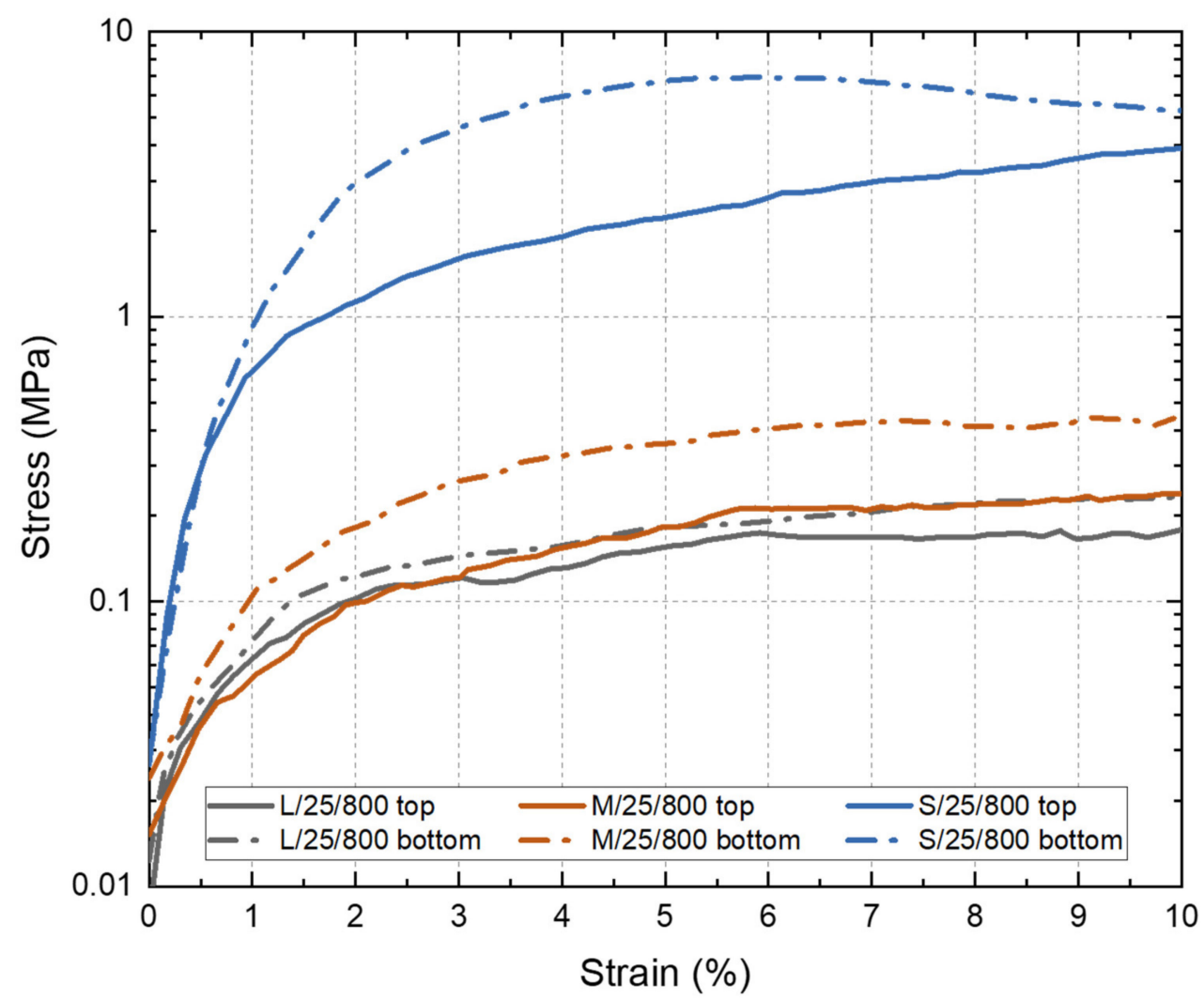

Figure 7. Stress-strain curves of the Ni wicks freeze-casted at $25^{\circ} \mathrm{C}$ and sintered at $800{ }^{\circ} \mathrm{C}$ according to the particle size range ( $\mathrm{S}, \mathrm{M}$, and $\mathrm{L})$. Compression tests were performed on samples extracted from the top (full line) and bottom (dotted line) sections of the Ni wicks.

\section{Conclusions}

The addition of PS as a camphene thickening additive and the use of a continuous freeze-casting method has proved successful to manufacture functional Ni wicks with a minimum of $80 \%$ of open porosity and almost uniform pore sizes. Pore size and pore morphology was influenced by the particles size used and the $F R$ applied during the freezecasting process. The pore morphology and the pore tortuosity seem to be the main factors 
to tailor the Ni-wick capillary performance. The use of higher $F R$ developed Ni-wicks with a faster absorption rate, regardless of the particle size employed. Therefore, Ni wicks $\mathrm{L} / 10 / 800, \mathrm{M} / 10 / 800$, and S/10/800 showed a better capillarity performance with the use of commercial grade Ni particle however, only the Ni wick S/10/800 complies with the mechanical property requirements.

Author Contributions: Conceptualization, R.S. and E.C.; methodology, R.S. and E.C.; formal analysis, R.S. and P.J.L.-J.; investigation, L.C., P.J.L.-J. and E.C.; resources, R.S.; writing-original draft preparation, R.S., E.C., P.J.L.-J. and L.C.; writing-review and editing, R.S., E.C., P.J.L.-J. and L.C.; visualization, L.C. and P.J.L.-J.; supervision, R.S.; project administration, R.S.; funding acquisition, R.S. All authors have read and agreed to the published version of the manuscript.

Funding: Financial support for this work has been provided by the Ministerio de Ciencia e InnovaciónAgencia Estatal de Investigación through the project MAT2016-76713-P co-funded by European Regional Development Fund. Lloreda-Jurado P.J. also thanks the University of Seville for its financial support (grant PIF II.2A, through VI Plan Propio de Investigación).

Institutional Review Board Statement: Not applicable.

Informed Consent Statement: Not applicable.

Data Availability Statement: The data presented in this study are available on request from the corresponding author.

Conflicts of Interest: The authors declare that they have no known competing financial interests or personal relationships that could have appeared to influence the work reported in this paper.

\section{References}

1. Vainoris, M.; Cesiulis, H.; Tsyntsaru, N. Metal Foam as a cathode for copper electrowinning. Coatings 2020, 10, 822. [CrossRef]

2. Li, Y.; Wang, X.; Wang, X.; Ren, Y.; Han, F.; Wen, C. Sound absorption characteristics of aluminum foam with spherical cells. J. Appl. Phys. 2011, 110, 113525. [CrossRef]

3. Singh, H.; Saxena, P.; Puri, Y.M. The manufacturing and applications of the porous metal membranes: A critical review. CIRP J. Manuf. Sci. Technol. 2021, 33, 339-368. [CrossRef]

4. Liu, J.; Gao, Y.; Fan, Y.; Zhou, W. Fabrication of porous metal by selective laser melting as catalyst support for hydrogen production microreactor. Int. J. Hydrogen Energy 2020, 45, 12-22. [CrossRef]

5. Li, Y.; Jahr, H.; Zhou, J.; Zadpoor, A.A. Additively manufactured biodegradable porous metals. Acta Biomater. 2020, 115, 29-50. [CrossRef] [PubMed]

6. Rodriguez-Contreras, A.; Punset, M.; Calero, J.A.; Gil, F.J.; Ruperez, E.; Manero, J.M. Powder metallurgy with space holder for porous titanium implants: A review. J. Mater. Sci. Technol. 2021, 76, 129-149. [CrossRef]

7. Pérez, A.; Ferreño, D.; Carrascal, I.A.; Polanco, J.A.; Casado, J.A.; Diego, S. Metal cushion dampers for railway applications: A review. Constr. Build. Mater. 2020, 238, 117711. [CrossRef]

8. Lin, T.; Gan, T.; Quan, X.; Cheng, P. Fabricating metal wicks by LMC-like continuous directional freeze casting. J. Mater. Process. Technol. 2020, 282, 116641. [CrossRef]

9. Maydanik, Y.F.; Chernysheva, M.A.; Pastukhov, V.G. Review: Loop heat pipes with flat evaporators. Appl. Therm. Eng. 2014, 67, 294-307. [CrossRef]

10. Samanta, S.K.; Das, P.; Lohar, A.K. Study of physical characteristics of nickel wicks developed by metal injection moulding. Powder Metall. 2013, 56, 221-230. [CrossRef]

11. Tian, W.; He, S.; Liu, Z.; Liu, W. Experimental investigation of a miniature loop heat pipe with eccentric evaporator for cooling electronics. Appl. Therm. Eng. 2019, 159, 113982. [CrossRef]

12. Zhang, S.; Chen, C.; Chen, G.; Sun, Y.; Tang, Y.; Wang, Z. Capillary performance characterization of porous sintered stainless steel powder wicks for stainless steel heat pipes. Int. Commun. Heat Mass Transf. 2020, 116, 104702. [CrossRef]

13. Reay, D.A.; Kew, P.A.; McGlen, R.J. Heat pipe components and materials. In Heat Pipes Theory, 6th ed.; Reay, D.A., Kew, P.A., McGlen, R.J., Dunn, P.D., Eds.; Butterworth-Heinemann: Oxford, UK, 2014; pp. 65-94, ISBN 978-00-8098-266-3.

14. Li, J.; Zou, Y.; Cheng, L.; Singh, R.; Akbarzadeh, A. Effect of fabricating parameters on properties of sintered porous wicks for loop heat pipe. Powder Technol. 2010, 204, 241-248. [CrossRef]

15. Choi, J.; Sano, W.; Zhang, W.; Yuan, Y.; Lee, Y.; Borca-Tasciuc, D.A. Experimental investigation on sintered porous wicks for miniature loop heat pipe applications. Exp. Therm. Fluid Sci. 2013, 51, 271-278. [CrossRef]

16. Jiang, L.; Tang, Y.; Zhou, W.; Jiang, L.; Xiao, T.; Li, Y.; Gao, J. Design and fabrication of sintered wick for miniature cylindrical heat pipe. Trans. Nonferrous Met. Soc. China 2014, 24, 292-301. [CrossRef]

17. Lloreda-Jurado, P.J.; Chicardi, E.; Paúl, A.; Sepúlveda, R. Effect of processing parameters on the properties of freeze-cast Ni wick with gradient porosity. Mater. Des. 2021, 206, 109795. [CrossRef] 
18. Scotti, K.L.; Dunand, D.C. Freeze casting-A review of processing, microstructure and properties via the open data repository, FreezeCasting.net. Prog. Mater. Sci. 2018, 94, 243-305. [CrossRef]

19. Lloreda-Jurado, P.J.; Pérez-Soriano, E.M.; Paúl, A.; Herguido, J.; Peña, J.A.; Sepúlveda, R. Doped iron oxide scaffolds with gradient porosity fabricated by freeze casting: Pore morphology prediction and processing parameters. Mater. Sci. Technol. 2020, 36, 1227-1237. [CrossRef]

20. Wegst, U.G.K.; Schecter, M.; Donius, A.E.; Hunger, P.M. Biomaterials by freeze casting. Philos. Trans. R. Soc. A Math. Phys. Eng. Sci. 2010, 368, 2099-2121. [CrossRef]

21. Felix, M.; Perez-Puyana, V.; Paúl, A.; Sepúlveda, R. Camphene/polystyrene solutions: A rheological approach for material processing industry. J. Appl. Polym. Sci. 2019, 136, 47953. [CrossRef]

22. Hildebrand, T.; Rüegsegger, P. A new method for the model-independent assessment of thickness in three-dimensional images. J. Microsc. 1997, 185, 67-75. [CrossRef]

23. Li, X.; Yao, D.; Zuo, K.; Xia, Y.; Zeng, Y.P. Effects of pore structures on the capillary and thermal performance of porous silicon nitride as novel loop heat pipe wicks. Int. J. Heat Mass Transf. 2021, 169, 120985. [CrossRef]

24. Grebenyuk, Y.; Zhang, H.X.; Wilhelm, M.; Rezwan, K.; Dreyer, M.E. Wicking into porous polymer-derived ceramic monoliths fabricated by freeze-casting. J. Eur. Ceram. Soc. 2017, 37, 1993-2000. [CrossRef]

25. Wang, D.; Wang, X.; Zhou, P.; Wu, Z.; Duan, B.; Wang, C. Influence of packing density on performance of porous wick for LHP. Powder Technol. 2014, 258, 6-10. [CrossRef]

26. Sen, S.; Kaukler, W.F.; Curreri, P.; Stefanescu, D.M. Dynamics of solid/liquid interface shape evolution near an insoluble particle-An X-ray transmission microscopy investigation. Metall. Mater. Trans. A Phys. Metall. Mater. Sci. 1997, 28, $2129-2135$. [CrossRef]

27. Park, H.; Um, T.; Hong, K.; Kang, J.S.; Nam, H.S.; Kwon, K.; Sung, Y.E.; Choe, H. Effects of Powder Carrier on the Morphology and Compressive Strength of Iron Foams: Water vs Camphene. Metall. Mater. Trans. B 2018, 49, 2182-2190. [CrossRef] 